\title{
Adapted Autoregressive Model and Volatility Model with Application
}

\author{
Naisheng Wang ${ }^{1}$ and Yan $\mathrm{Lu}^{2 *}$ \\ ${ }^{1}$ China Securities Index Co., Ltd and ${ }^{2}$ University of New Mexico
}

\begin{abstract}
Price limits are applied to control risks in various futures markets. In this research, we proposed an adapted autoregressive model for the observed futures return by introducing dummy variables that represent limit moves. We also proposed a stochastic volatility model with dummy variables. These two models are used to investigate the existence of price delayed discovery effect and volatility spillover effect from price limits. We give an empirical study of the impact of price limits on copper and natural rubble futures in Shanghai Futures Exchange (SHFE) by using MCMC method. It is found that price limits are efficient in controlling copper futures price, but the rubber futures price is distorted significantly. This implies that the effects of price limits are significant for products with large fluctuation and frequent limits hit.
\end{abstract}

Key words: Autoregressive model, MCMC sampling, price delayed discovery effect, price limits, stochastic volatility model.

\section{Introduction}

More than two thirds of the organized markets in the world have price limits (Hall and Kofman, 2001). Price limits describe the highest and lowest prices that a commodity or option is permitted to reach in a given trading session. It is an important regulation to control risks and to inhibit excessive fluctuation of futures price.

The use of price limits in futures markets has generated a great deal of discussion since the global market crash of 1987. After a study of the U.S Treasury Bond Futures behavior, Ma and Rao and Sears (1989a, 1989b) found that price limits could prevent the overreaction of futures markets to the fundamental markets information. Price may deviate from the true equilibrium price after reaching the limit. But the deviation is temporary and will disappear soon. Therefore, it will

${ }^{*}$ Corresponding author. 
not affect the price-discovery process. Brennan (1986) and Moser (1990) pointed out that price limits could serve to reduce the potential reneging of the contracts. The references that consider positive effects of price limits can also be found from Anderson (1984), Greewald and Stein (1991), Arak and Cook (1997) and so on. However, most of the studies do not support the theory of positive effects of price limits. They showed that by preventing price from converging to the equilibrium price effectively, price limits would slow down the price-discovery process and make markets inefficient. Therefore, price limits are useless. Such studies include Figlewsk (1984), Lehmman (1989), Fama (1989) and Kim and Rhee (1997) etc. Jiang and Konstantinidi and Skiadopoulos (2012) also proposed a novel approach to examine the effect of US and European news announcements on the spillover of volatility across US and European Stock markets.

The effectiveness of price limits are usually examined according to price delayed discovery effect, volatility spillover effect and trading disturbance effect. When a limit is reached, trading stops and the equilibrium price is not observed. Under hypothesis of price delayed discovery effect, price will continue to reach equilibrium price during the following trading days. Under hypothesis of volatility spillover effect, trading following a limit move will reflect unrealized fluctuations of that day. Therefore the period of price fluctuation extends to a longer one. Generally, if the hypotheses of price delayed discovery effect and volatility spillover effect are accepted, it is considered that price limits are useless.

In this paper, we proposed an autoregressive model for the observed futures return by introducing dummy variables that represent limit moves. We also proposed a stochastic volatility model with dummy variables. Using these two models, we investigate the existence of price delayed discovery effect and volatility spillover effect of copper and natural rubber futures in SHFE. Due to the difficulty of data collection, we didn't discuss trading disturbance effect. This paper consists of five Chapters. Chapter 2 discusses the realization of price delayed discovery effect and volatility spillover effect. Chapter 3 proposes adapted time series models and discusses parameter estimation and hypothesis testing. Chapter 4 presents an empirical study of the effects of price limits in SHFE. Lastly, we give a conclusion in Chapter 5 .

\section{The Influence of Price Limits on Futures Price}

In this section, first, we review futures return under price limits. We decompose the true equilibrium futures return in three parts: the observed return, the unrealized part of that trading day and the unrealized equilibrium return carried over from the previous trading day. Based on our decomposition, we discuss price delayed discovery effect. Then we discuss volatility spillover effect. 


\subsection{Futures Return under Price Limits}

In a market with a daily price limit, trading is permitted only at prices within limits determined by the settlement price of the previous day. In Chinese futures markets, the absolute variation is $3 \%$ around settlement price of the previous day under normal situation. If the bid is outside the allowed trading range, it is considered invalid. Therefore if equilibrium price moves outside the limits, price limits are the price we observe. The relationship between the observed futures price and equilibrium price at $t^{\text {th }}$ trading day can be described as the following:

$$
F_{t}= \begin{cases}F_{t-1}(1+l), & \text { if } F_{t}^{e} \geq F_{t-1}(1+l) \\ F_{t}^{e}, & \text { if } F_{t-1}(1-l)<F_{t}^{e}<F_{t-1}(1+l) \\ F_{t-1}(1-l), & \text { if } F_{t}^{e} \leq F_{t-1}(1-l)\end{cases}
$$

where $F_{t}^{e}$ is the equilibrium price at time $t, F_{t}$ is the observed price and $l$ is the maximum daily limit imposed on the absolute change in futures price within a trading day. In Chinese futures markets $l=3 \%$. The observed futures price is equal to the true equilibrium price only if the futures equilibrium price falls within the price limits. If the futures price we observe is equal to the limits, the true equilibrium price must be higher (or lower) than the price observed.

The $\log$ returns $\log \left(F_{t} / F_{t-1}\right)$ is commonly used during empirical study. It can be written as the following:

$$
r_{t}= \begin{cases}r^{u}, & \text { if } F_{t}^{e} \geq F_{t-1}(1+l) \\ \ln \left(F_{t}^{e} / F_{t-1}\right), & \text { if } F_{t-1}(1-l)<F_{t}^{e}<F_{t-1}(1+l) \\ r^{d}, & \text { if } F_{t}^{e} \leq F_{t-1}(1-l)\end{cases}
$$

where $r_{t}=F_{t} / F_{t-1}, r^{u}=\ln (1+l)$, and $r^{d}=\ln (1-l) . r^{u}$ and $r^{d}$ are the limit-up and limit-down of futures log return respectively. We can see that the observed return is not necessarily equal to the true equilibrium return. This is determined by the fact whether futures price of the previous trading day reaches the limits or not.

\subsection{Price Delayed Discovery Effect}

Chou and $\mathrm{Wu}$ (1998) decomposed the equilibrium return as the sum of the observed return and the unrealized parts from the current trading day. They didn't consider the part carried over from the previous trading day. Therefore their conclusion is not suitable for the situation of consecutive limit hits.

In the following, we decompose the true equilibrium futures return as three 
parts:

$$
\begin{aligned}
r_{t}^{e} & =\ln \left(F_{t}^{e} / F_{t-1}^{e}\right) \\
& =\ln \left(F_{t} / F_{t-1}\right)+\ln \left(F_{t}^{e} / F_{t}\right)-\ln \left(F_{t-1}^{e} / F_{t-1}\right) \\
& =r_{t}+E_{t}-E_{t-1},
\end{aligned}
$$

where $E_{t}=\ln \left(F_{t}^{e} / F_{t}\right)$ denotes the unrealized part of equilibrium return at the $t^{\text {th }}$ trading day because of the existence of price limits. From (3), we see that equilibrium return is equal to the sum of the observed return and the unrealized part of that trading day subtracting the unrealized equilibrium return carried over from the previous trading day. Particularly, if there is no limit move at $(t-1)^{\text {th }}$ trading day, $E_{t-1}=0$; if there is no limit move at $t^{\text {th }}$ trading day, $E_{t}=0$. Otherwise, the unrealized part of equilibrium return will be carried over to the next trading day. This is called price delayed discovery effect (see Figure $1)$.

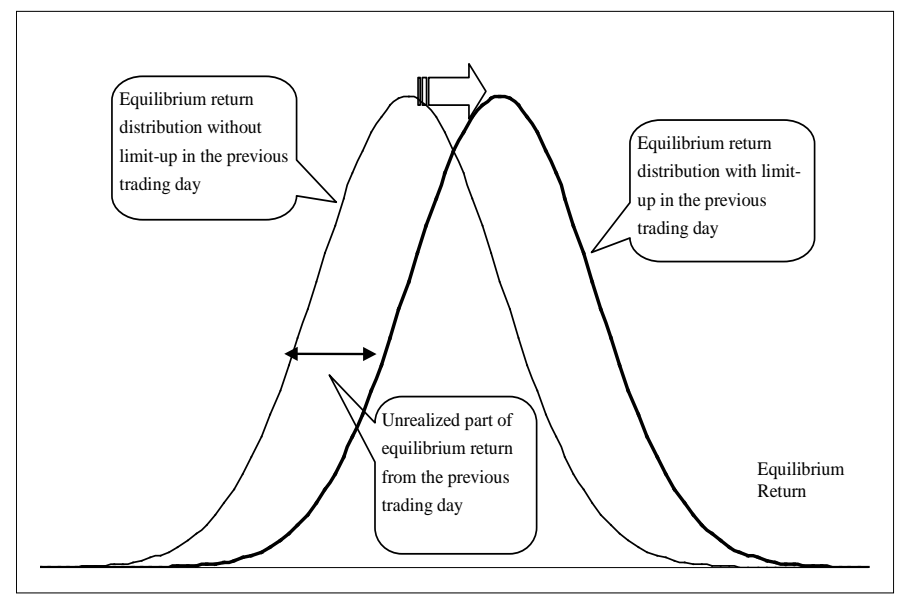

Figure 1

The distribution on the right is the futures equilibrium return of the day following a limit-up. The unrealized part of equilibrium return from the previous trading day is carried over to the next trading day.

If price reaches the upper limit at the $t^{\text {th }}$-trading day, the estimated equilibrium return with price limits at that day is:

$$
\hat{r}_{t}^{e}=E\left[r_{t}^{e} \mid r_{t}^{e}>r^{u}\right]
$$

(4) is the conditional expected return given the equilibrium return greater than the limit-up return (see Figure 2). 


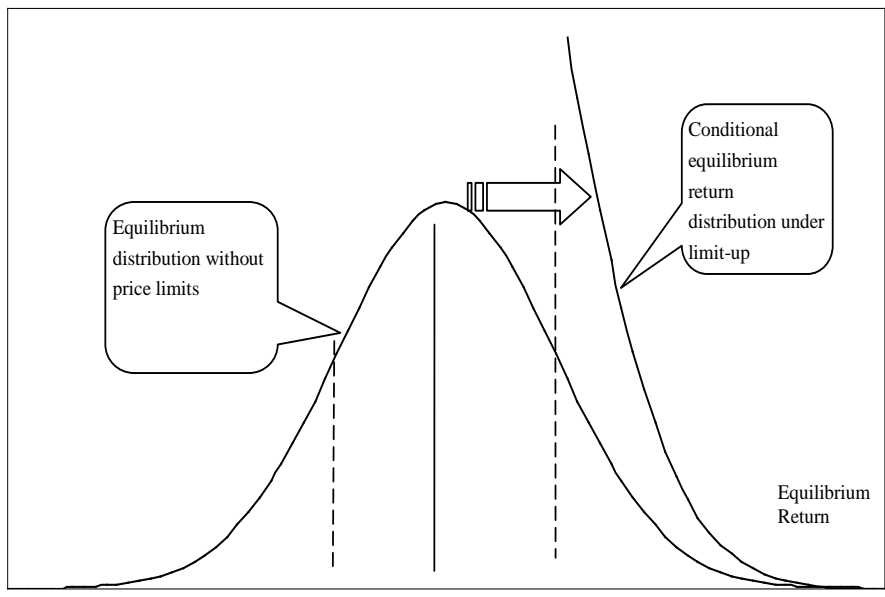

Figure 2

In Figure 2, between the two straight lines, we see the distribution under the price limits. The curve on the right indicates the conditional equilibrium return distribution under limit-up.

The equilibrium return of the next trading day is:

$$
\left.\hat{r}_{t+1}^{e}\right|_{r_{t}^{e}}=E\left[r_{t+1}^{e} \mid r_{t}^{e}>r^{u}\right] .
$$

Suppose equilibrium return follows the simple stochastic model:

$$
r_{t}^{e}=\mu+\varepsilon_{t},
$$

where $\varepsilon_{t}$ is a sequence of independent, identically distributed, random variables with mean 0 and variance $\sigma_{t}^{2}$. By (4) and (5) we obtain (7):

$$
\begin{aligned}
E\left[r_{t+1}^{e} \mid r_{t}^{e}>r^{u}\right] & =2 \mu+\phi\left(\Xi_{t}\right) /\left[1-\Phi\left(\Xi_{t}\right)\right]-r^{u} \\
& \geq \mu=E\left[r_{t+1}^{e}\right],
\end{aligned}
$$

where $\Xi_{t}=\left(r^{u}-\mu\right) / \sigma_{t}$. (7) indicates that futures price tends to go up following a limit-up day. On average, equilibrium return is greater than the equilibrium return without the enforcement of price limits. This is due to the price delayed discovery effect. Similarly, the futures price following a limit-down day tends to go down. Expected equilibrium return is lower than the expected equilibrium return without price limits. The same conclusion can be derived even we replace (6) by a more complicated model such as autoregressive processes. Trading stops when price reaches the limits. Under hypothesis of price delayed discovery effect, futures price will continue to go up or fall to reach equilibrium price in the following trading days, at least the next trading day. 


\subsection{Volatility Spillover Effect}

Consider model (6) again. When price reaches the upper limit at the $t^{\text {th }}$ day, variance of conditional equilibrium return of the next trading day is given as the following:

$$
\begin{aligned}
\operatorname{Var}\left[r_{t+1}^{e} \mid r_{t}^{e}>r^{u}\right] & =\sigma_{t+1}^{2}+\sigma_{t}^{2}\left\{1-\frac{\phi\left(\Xi_{t}\right)}{1-\Phi\left(\Xi_{t}\right)}\left[\frac{\phi\left(\Xi_{t}\right)}{1-\Phi\left(\Xi_{t}\right)}-\Xi_{t}\right]\right\} \\
& \geq \sigma_{t}^{2}=\operatorname{Var}\left[r_{t}^{e}\right] .
\end{aligned}
$$

The result is similar even with a more complicated model. Because of the high volatility at the limit-hit-day, large fluctuation will continue in the following days. This indicates that futures return sequence is volatility clustering. Price fluctuation of the next trading day following a limit-hit-day will be larger than the fluctuation without price limits. This is called volatility spillover effect.

Volatility spillover effect and price delayed discovery effect is highly related. The unrealized part of the equilibrium return because of price limits will deliver to the next trading day. This part of return is uncertain. Consequently, the uncertainty of return of the following trading day will increase, resulting in fluctuation increscent. Price limits impede price fluctuation that should be completed within one trading day. This results in a longer period of price fluctuation and volatility spillover. As a result, price limits could prevent price slump and price jump, could reduce risk and could make markets more rational.

\section{Testing Hypothesis and Methods}

In this section, we discuss how to test price delayed discovery effect and volatility spillover effect. In literature, many researchers adopt case study. They investigate the effect of price limits by comparing futures return and fluctuation before the limit move to those after the limit move. These methods work well for stock markets, where a lot of limit moves are observed and different stocks can be studied together. However, it is not efficient in futures markets, where a single futures product is unlikely to have lots of limit moves and different futures are not supposed to study together because of different features. For example, there are only about 20 limit moves of copper futures in SHFE within four years (1999-2003). A futures product has several contracts at the same time, but they may have similar behavior because of arbitrage. If we consider these contracts together, it is actually duplicate computations on the same price. Furthermore, case studies are hard to deal with the phenomena of consecutivelimit moves. Therefore, we propose a means model for the observed futures return with introducing dummy variables that represent limit moves. We also propose 
a stochastic volatility model with dummy variables. MCMC sampling method is used to estimate the parameters and test hypothesis.

\subsection{Adapted Autoregressive Model}

Generally we assume that the equilibrium return sequence is an autoregressive process $(\mathrm{AR}(1))$, i.e.,

$$
r_{t}^{e}=\mu+\varphi r_{t-1}^{e}+\varepsilon_{t},
$$

where, $(\mu, \varphi)$ are parameters, $\varepsilon_{t}$ is the error term with mean zero. MCMC method and EM algorithm can be used to analyze the above model (Wei, 2002). There are some other researchers who consider dummy variables that reflect price limits in the above model (Chou and $\mathrm{Wu}, 1998$ ). We believe the true equilibrium return is inherent, which would not be affected by the existence of price limits. What has been affected is the observed return. As a result, in order to examine if price limits have impact on price delayed discovery effect, it is not appropriate to introduce dummy variable in equilibrium return model. We need to construct a model for the observed return and introduce dummy variable. The model we proposed is as follows:

$$
r_{t}=\mu+\varphi r_{t-1}+\gamma \delta_{t-1}^{u}+\kappa \delta_{t-1}^{d}+\varepsilon_{t}, \quad \varepsilon_{t} \sim \mathcal{N}\left(0, \sigma_{t}^{2}\right),
$$

where $\sigma_{t}$ is volatility; $\delta_{t-1}^{u}$ and $\delta_{t-1}^{d}$ are the dummy variables reflecting whether there is a limit up or a limit down respectively. They are given as follows:

$$
\delta_{t-1}^{u}=\left\{\begin{array}{ll}
1, & r_{t-1}=r^{u}, \\
0, & r_{t-1}<r^{u},
\end{array} \quad \delta_{t-1}^{d}= \begin{cases}1, & r_{t-1}=r^{d} \\
0, & r_{t-1}>r^{d}\end{cases}\right.
$$

Following a limit up day, price return will move from $\mu+\varphi r_{t-1}$ to $\mu+\varphi r_{t-1}+\gamma$; following a limit down day, price return will move from $\mu+\varphi r_{t-1}$ to $\mu+\varphi r_{t-1}+k$. The null hypothesis and alternative hypothesis are given below:

$$
H_{0}^{1}: \gamma=0, \kappa=0 \quad \text { vs } \quad H_{1}^{1}: \gamma \neq 0, \kappa \neq 0 .
$$

Whether $\gamma$ equals zero or not indicates whether limit up has impact on price delayed discovery effect or not. Similarly, whether $k$ equals zero or not indicates whether limit down has impact on price delayed discovery effect or not.

\subsection{Volatility Model}

When studying price volatility, Chou and Wu (1998) assume that volatility is a constant when there are no limit moves. Although volatility spillover is one of the reasons of volatility clustering and other heteroscedastic characteristics 
indicated from the financial asset return sequence, there exists volatility clustering phenomena in some futures markets without price limits. So it is not ok to consider heteroscedastic characteristics as the result of price limits. Therefore we use heteroscedastic Volatility Model in our study.

The popular Volatility Models are GARCH (Engle, 1982) model and Stochastic Volatility model (SV model) (Taylor, 1986). These models can accurately describe the special characteristic of the financial data that has conditional fluctuation depending on time. Comparing to GARCH model, SV model has the following advantages: (1) SV model considers historical data and the newest information, which makes the prediction more acceptable; (2) SV model can easily reflects leverage of different types of information. Although GARCH model can also reach this goal after revising, it introduces more parameters; (3) SV model is more flexible comparing to GARCH model with fewer restrains on parameter estimation and testing hypothesis. In addition, SV model can show the fat tail characteristic of asset return sequence. With the recent development of MCMC computing techniques, parameter estimation of SV model is no longer a problem. Therefore, we use SV model to be futures return volatility model.

Generally, suppose volatility follows the SV(1) process:

$$
\begin{aligned}
& \sigma_{t}=\exp \left(h_{t} / 2\right), \\
& h_{t}=\omega+\psi\left(h_{t-1}-\omega\right)+\eta_{t}, \quad \eta_{t}=\mathcal{N}\left(0, \tau^{2}\right),
\end{aligned}
$$

where $\psi \in(-1,1), \eta_{t}$ and $\varepsilon_{t}$ are mutually independent. Stochastic volatility model considers the logarithm of volatility as an autoregressive process, which is time-dependent. Autoregressive coefficient $\psi$ shows sustained status of fluctuation. $\eta_{t}$ denotes the potential information from trading day $t-1$ to trading day $t$. In order to investigate the impact on futures price volatility due to price limits, we introduce a dummy variable that represents whether there is a limit move or not. The above model becomes:

$$
h_{t}=\omega+\psi\left(h_{t-1}-\omega\right)+\zeta \delta_{t-1}^{u}+\lambda \delta_{t-1}^{d}+\eta_{t} .
$$

The coefficients of dummy variables show the influence of price limits on volatility. $\zeta>0(\lambda>0)$ indicates that volatility increases because of limit move, resulting volatility spillover. $\zeta<0(\lambda<0)$ indicates that volatility decreases after limit move. Otherwise, $\zeta=0(\lambda=0)$ indicates no influence on volatility from price limits. The null hypothesis and alternative hypothesis are as the following:

$$
H_{0}^{2}: \zeta=0, \lambda=0 \quad \text { vs } \quad H_{1}^{2}: \zeta \neq 0, \lambda \neq 0 .
$$

If $H_{0}^{2}$ is rejected, we conclude that $\zeta$ and $\lambda$ differ from 0 significantly and there exists volatility spillover effect. 


\subsection{Parameter Estimation and Testing Methods}

Parameter estimation is the major problem that restricts the application of SV model. Methods such as least square estimation, maximum likelihood estimation and other methods do not work. Current popular methods for parameter estimation of SV model include pseudo likelihood method, generalized moment method and MCMC sampling method. All of these methods require a lot of computation. MCMC sampling method is one of the efficient ways to estimate the parameters of SV model. The basic idea of MCMC is from Bayes method. MCMC sampling method considers the parameters as random variables, assigns parameters certain prior distributions and calculates their posterior distributions. Random numbers are drawn from conditional posterior distribution to estimate the parameters.

Let $\xi$ be a vector of random variables with $(\mu, \varphi, \gamma, \kappa, \omega, \psi, \zeta, \lambda, \tau)$. We set up the prior distribution as the following non-informative improper prior:

$$
\pi_{0}(\mu, \varphi, \gamma, \kappa, \omega, \psi, \zeta, \lambda, \tau) \propto 1,
$$

where

$$
\begin{aligned}
& \mu \in(-\infty,+\infty), \varphi \in(-1,1), \gamma \in(-\infty,+\infty), \quad \kappa \in(-\infty,+\infty), \\
& \omega \in(-\infty,+\infty), \psi \in(-1,1), \quad \zeta \in(-\infty,+\infty), \lambda \in(-\infty,+\infty), \tau \in(0, \infty) .
\end{aligned}
$$

To ensure model stability of (9) and (11), we restrict $\varphi$ and $\psi$ between -1 and 1. Let $\boldsymbol{r}=\left\{r_{t}, t=1, \cdots, T\right\}$ be the return vector and $\boldsymbol{h}=\left\{h_{t}, t=1, \cdots, T\right\}$ be the $\log$ volatility vector. Based on (9), we can get the likelihood function of the return sequence $\left\{r_{t}\right\}$ as the following:

$$
L(\xi, \boldsymbol{h} \mid \boldsymbol{r})=\prod_{t=1}^{T} p\left(r_{t} \mid r_{t-1}, h_{t}, \xi\right) p\left(h_{t} \mid h_{t-1}, \xi\right) .
$$

Under the condition that the prior distribution is non-informative, the joint posterior distribution function of the parameters and $\boldsymbol{h}$ is

$$
\pi(\xi, \boldsymbol{h} \mid \boldsymbol{r})=L(\xi, \boldsymbol{h} \mid \boldsymbol{r}) / \int L(\xi, \boldsymbol{h} \mid \boldsymbol{r}) d \boldsymbol{r} .
$$

Therefore, Bayes estimator of the parameters are given by:

$$
\hat{\xi}=\iint \xi \pi(\xi, \boldsymbol{h} \mid \boldsymbol{r}) d \boldsymbol{h} d \xi .
$$

Notice the dimension of the vector $\boldsymbol{h}$ is the same as the number of the observed data, calculating the above integral directly is impossible. MCMC sampling 
method, Berger (1985) is a recently developed efficient Bayes computational method. Its basic idea is to obtain a sample $\pi(\xi, \boldsymbol{h} \mid \boldsymbol{r})$ by constructing a Markov Chain with stationary distribution $\pi(\xi, \boldsymbol{h} \mid \boldsymbol{r})$. Various statistical inferences are then derived based on these samples and large number theory.

The most popular MCMC sampling method is Gibbs sampling. Let $\boldsymbol{\theta}=$ $(\mu, \varphi, \kappa, \gamma, \omega, \psi, \zeta, \lambda, \tau, \boldsymbol{h})$, following is the basic steps:

Step 1 : Calculate the stationary distribution $\pi\left(\theta_{i} \mid \boldsymbol{\theta}_{\neq i}, \boldsymbol{r}\right)$, where $\boldsymbol{\theta}_{\neq i}$ denotes the vector without $\theta_{i}$.

Step 2 : Choose a starting point $\boldsymbol{\theta}^{(0)}$ such that $\boldsymbol{\theta}^{(0)}=\left(\theta_{1}^{(0)}, \cdots, \theta_{k}^{(0)}\right)$, where $k$ is the length of vector $\boldsymbol{\theta}$;

Step 3: Draw $\theta_{i}^{(j)}$ from stationary distribution $\pi\left(\theta_{i} \mid \boldsymbol{\theta}_{\neq i}^{(j-1)}, \boldsymbol{r}\right)(i=1,2, \cdots, k)$;

Step 4 : Repeat Step 3, sampling $N$ times after convergence;

Step 5 : Use the $N$ samples after convergence to perform statistical inference.

Based on the sample obtained by MCMC method, we can estimate the parameters of model (9) and (11) and perform hypothesis testing and other statistical inference. In the later empirical study, besides estimating the parameters, we also calculate the highest posterior density (HPD) interval of the coefficients of dummy variables at certain significance level. In terms of HPD interval (Berger, 1985), we use observed data and the resulted posterior distribution to find a minimum interval within the domain of parameters such that the probability of the parameters in the interval reaches the required confidence level. If the HPD interval includes null hypotheses $H_{0}^{1}$ and $H_{0}^{2}$, we have no reason to reject $H_{0}^{1}$ and $H_{0}^{2}$.

\section{Empirical Studies}

\subsection{Data}

Currently there are three futures products: copper, aluminum and natural rubber futures in SHFE. Aluminum futures price is quite stable with seldom limits hit. Therefore copper and natural rubber is used in our study. Data we use for study consists daily closing price and settlement price during three-month contract. Table 1 gives the information of the dataset. During the period (19992003), each product experienced from recession to market bubble. Therefore, data is representative.

Table 1: Description of data 


\begin{tabular}{lcccccc}
\hline & $\begin{array}{c}\text { Beginning and } \\
\text { ending date }\end{array}$ & $\begin{array}{c}\text { Trading } \\
\text { days }\end{array}$ & $\begin{array}{c}\text { Minimum } \\
\text { volatility unit }\end{array}$ & $\begin{array}{c}\text { Days } \\
\text { of up } \\
\text { limits } \\
\text { hit }\end{array}$ & $\begin{array}{c}\text { Days } \\
\text { of lower } \\
\text { limits } \\
\text { hit }\end{array}$ & $\begin{array}{c}\text { Frequency } \\
\text { of } \\
\text { limits } \\
\text { hit }\end{array}$ \\
\hline $\begin{array}{l}\text { Copper } \\
\text { futures }\end{array}$ & $\begin{array}{c}1999 / 2 / 23- \\
2003 / 11 / 20\end{array}$ & 1096 & 10 RMB & 13 & 9 & $2.02 \%$ \\
\hline $\begin{array}{l}\text { Natural } \\
\text { rubber } \\
\text { futures }\end{array}$ & $\begin{array}{c}1999 / 5 / 19- \\
2003 / 11 / 20\end{array}$ & 1029 & 5 RMB & 34 & 28 & $6.03 \%$ \\
\hline
\end{tabular}

In practice, when judging whether there is a limit hit or not, we do not strictly follow the described percentage, but consider the minimum tick size of the contracts. If we use $\Delta$ to denote the minimum tick size and use $S P_{t}$ to represent settlement price of $t^{\text {th }}$ trading day, the price limits of $(t+1)^{\text {th }}$ trading day is:

$$
P_{t+1}^{u}=\Delta \times \operatorname{int}\left(\frac{S P_{t}(1+l)}{\Delta}\right), \quad P_{t+1}^{d}=\Delta \times \operatorname{ceil}\left(\frac{S P_{t}(1-l)}{\Delta}\right),
$$

where function $\operatorname{int}(x)$ is the largest integer not greater than $x$ and ceil $(x)$ is the smallest integer not less than $x$. If the price is higher than $P_{t+1}^{u}$, a limit up happens. If the price is lower than $P_{t+1}^{d}$, a limit down happens. This rule is slightly different from the rule of the futures exchange.

Table 1 gives the beginning and ending dates of the data in our study, number of trading days and information on limit hits of both futures products.

From Table 1, we notice that frequency of limits hit is quite different between the two futures products, indicating the difference of fluctuation and risk between these two products. The high frequency of limits hit of natural rubber indicates high price volatility and high risk of this product. The relatively lower frequency of limits hit of copper futures indicates relative stability and relative lower risk of this product.

\subsection{Empirical Results and Analysis}

We generate MCMC samples for the parameters of models (9) and (11) using BUGS and SAS software. The result indicates that the sequence converges around 4000 times sampling (Figure 3). We then continue with another 16000 sampling. The converged sampling sequence is used to estimate the parameters. Figure 4 gives the distributions of sampling sequences of dummy variables after convergence, which are asymptotically symmetric. So we can determine $90 \%$ HPD confidence interval by calculating its $5 \%$ and $95 \%$ quartiles. 
Table 2 gives the estimator, standard deviation, MCMC sampling error and HPD confidence interval of each parameter. Table 3 gives a summary of the effects of price limits on copper and natural rubber.

Table 2: The results of MCMC estimation

\begin{tabular}{ccccc}
\hline Parameter & Mean & $\begin{array}{c}\text { Standard } \\
\text { deviation }\end{array}$ & Sampling error & $90 \%$ HPD interval \\
\hline \multicolumn{4}{c}{ Copper } \\
\hline$\mu\left(10^{-2}\right)$ & -0.0046 & 0.0214 & 0.0007 & \\
$\varphi\left(10^{-2}\right)$ & -9.2380 & 3.4450 & 0.1172 & $(-0.0512,1.1720)$ \\
$\gamma\left(10^{-2}\right)$ & 0.5560 & 0.3730 & 0.0086 & $(-0.8778,0.3810)$ \\
$\kappa\left(10^{-2}\right)$ & -0.2478 & 0.3879 & 0.0077 & \\
$\omega$ & -9.7370 & 0.1964 & 0.0085 & $(-0.2464,0.5244)$ \\
$\psi$ & 0.9379 & 0.0262 & 0.0023 & \\
$\zeta$ & 0.1317 & 0.2351 & 0.0195 & \\
$\lambda$ & -0.3547 & 0.2999 & 0.0232 & $(-0.8462,0.1385)$ \\
$\tau$ & 0.2646 & 0.0537 & 0.0052 & $(-1.2700,0.0599)$ \\
\hline & & Natural rubber & \\
\hline$\mu\left(10^{-2}\right)$ & 0.0014 & 0.0241 & 0.0008 & $(-0.1228,0.4826)$ \\
$\varphi\left(10^{-2}\right)$ & -8.1730 & 3.5620 & 0.1004 & $0.5657)$ \\
$\gamma\left(10^{-2}\right)$ & 1.0800 & 0.3350 & 0.0099 & \\
$\kappa\left(10^{-2}\right)$ & -0.6022 & 0.4060 & 0.0136 & \\
$\omega$ & -9.4560 & 0.2010 & 0.0076 & \\
$\psi$ & 0.9039 & 0.0281 & 0.0022 & \\
$\zeta$ & 0.1633 & 0.1843 & 0.0118 & 0.0145 \\
$\lambda$ & 0.1931 & 0.2168 & 0.0054 & \\
$\tau$ & 0.4753 & 0.0590 & $0370)$ \\
\hline
\end{tabular}

Table 3: A summary of the effect of price limits on copper and natural rubber futures

\begin{tabular}{cccccc}
\hline & \multicolumn{2}{c}{ Upper Limit } & & \multicolumn{2}{c}{ Lower Limit } \\
\cline { 2 - 3 } \cline { 5 - 6 } Copper & Slightly delay & $\begin{array}{c}\text { Slightly } \\
\text { spillover }\end{array}$ & & $\begin{array}{c}\text { Slightly pulling } \\
\text { back }\end{array}$ & Slightly decreasing \\
\hline Natural rubber & $\begin{array}{c}\text { Significantly } \\
\text { delay }\end{array}$ & $\begin{array}{c}\text { Slightly } \\
\text { spillover }\end{array}$ & $\begin{array}{c}\text { Slightly pulling } \\
\text { back }\end{array}$ & Slightly spillover \\
\hline
\end{tabular}

\subsubsection{Price Delayed Discovery Effect}

For copper futures, although both the estimated coefficients of dummy variables $\gamma$ and $k$ in the means model are not equal to zero, both of the 90\% HPD con- 
fidence intervals include zero, so we don't reject the null hypotheses $H_{0}^{1}: \gamma=0$, $\kappa=0$. Price limits didn't have significant price delayed discovery effect on copper futures. Coefficient $\gamma$ is greater than zero, indicating slight price delayed discovery effect. Coefficient $\kappa$ is less than zero, indicating that price will be pulled back in the following trading days. Overreaction exists in copper futures markets, which is corrected in the following trading days.

For natural rubber futures, the estimated coefficient of $\gamma$ in the means model is not equal to zero and zero is outside its $90 \%$ HPD confidence interval. The hypothesis $\gamma=0$ is therefore rejected. There is significant price delayed discovery effect on natural rubber futures due to limit up. Coefficient $k$ is less than zero, but zero is inside its $90 \%$ HPD confidence interval, indicating slight delayed discovery effect of natural rubber futures price after limit down.

\subsubsection{Volatility Spillover Effect}

For copper futures and natural rubber volatility model, all the 90\% HPD confidence intervals of dummy variables include zero. We can't reject hypothesis $H_{0}^{2}$ for both products. This indicates that no significant volatility spillover effect on copper futures and natural rubber futures is due to price limits. Both of the dummy variables of limit up are not equal to zero, indicating slight volatility spillover effect on copper futures and natural rubber futures because of limit up. Coefficients of limit down of copper futures and natural rubber futures are less than zero and greater than zero respectively, indicating that there is slight decrease of copper futures return volatility following limit down. This means that price limits have cooling-effect on the copper investors. While natural rubber futures return volatility has slight spillover phenomena.

From the above analysis, price limits have no adverse impact on copper futures price. It is efficient to control risks for copper futures. For natural rubber, limit down has no adverse impact, while the limit up hinder futures price-discovery process.

The difference between the effects of price limits on natural rubber futures and copper futures is related to the different markets behavior of these two products. Copper futures are relatively stable with few limits hit. The frequency of limits hit is only $2.02 \%$. While the frequency of limits hit of natural rubber futures is $6.03 \%$. Price limits have more influence on active futures products than the relatively stable ones.

When studying the effect of price limits on stock price, Kim and Limpaphayom (2000) pointed out those different effects from price limits existed because of different characteristics of stocks. Based on our study, their conclusions can be extended to futures markets.

Table 2 gives the estimator, standard deviation, MCMC sampling error of 
each parameter and HPD confidence interval of the dummy variables.

Table 3 gives a summary of the effect of price limits on copper and natural rubber. Price limits have no adverse impact on copper futures price. It is efficient to control risks for copper futures. For natural rubber, limit down has no adverse impact, while the limit up hinder futures price-discovery process.

\section{Conclusions}

This paper studies the effect of price limits on SHFE theoretically and empirically using autoregressive model, stochastic volatility model and MCMC sampling techniques. The authors have the following findings: (1) Price limits have no adverse impact on copper futures price. They are efficient to control risks. For natural rubber futures, although price limits efficiently control risks, it impede futures price discovery process. (2) The influence on futures price from price limits relies on characteristics of futures products. Influence is significant for products with large fluctuation and frequent limits hit. This finding implies that the effect of price limits on futures price relies heavily on nature of futures products and the price limits on rubber futures should be adjusted.

Appendix: Sampling Sequences and Sampling Distributions of the Coefficients of Dummy Variables for Natural Rubber Futures
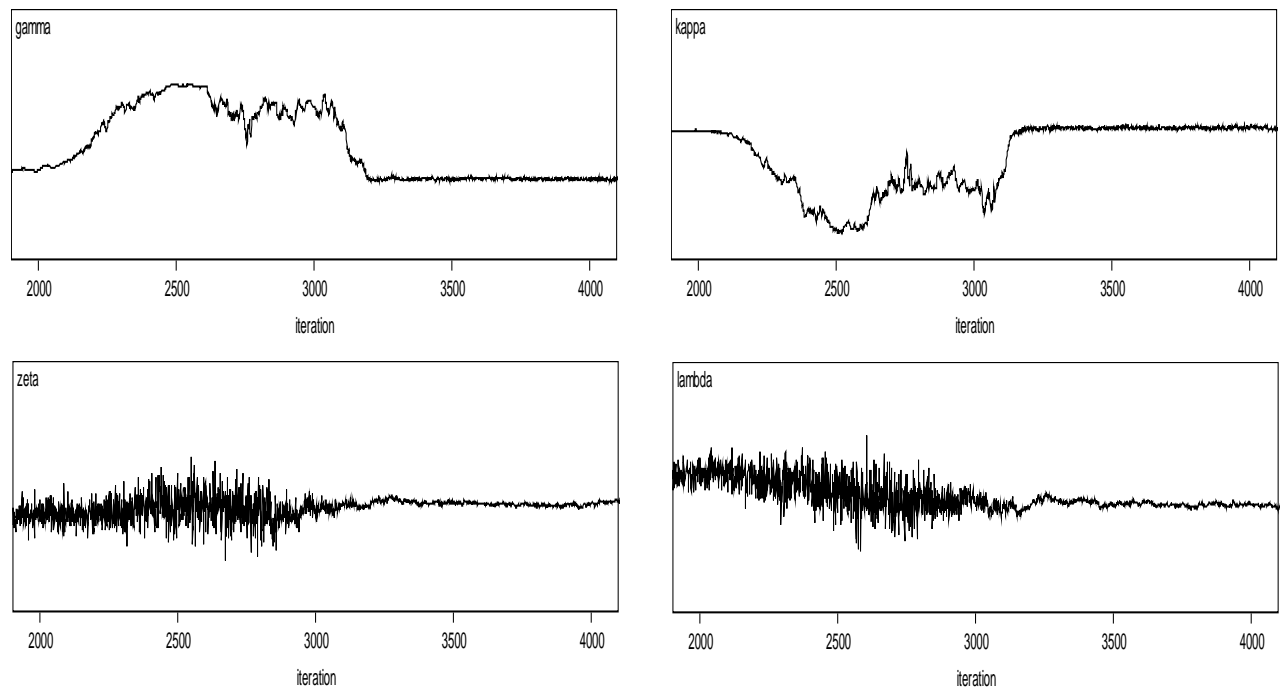

Figure 3

Figure 3 gives a description of the convergence of the sampling sequences of the coefficients of dummy variables for Natural Rubber Futures. The sequences converge around 3100 sampling. 

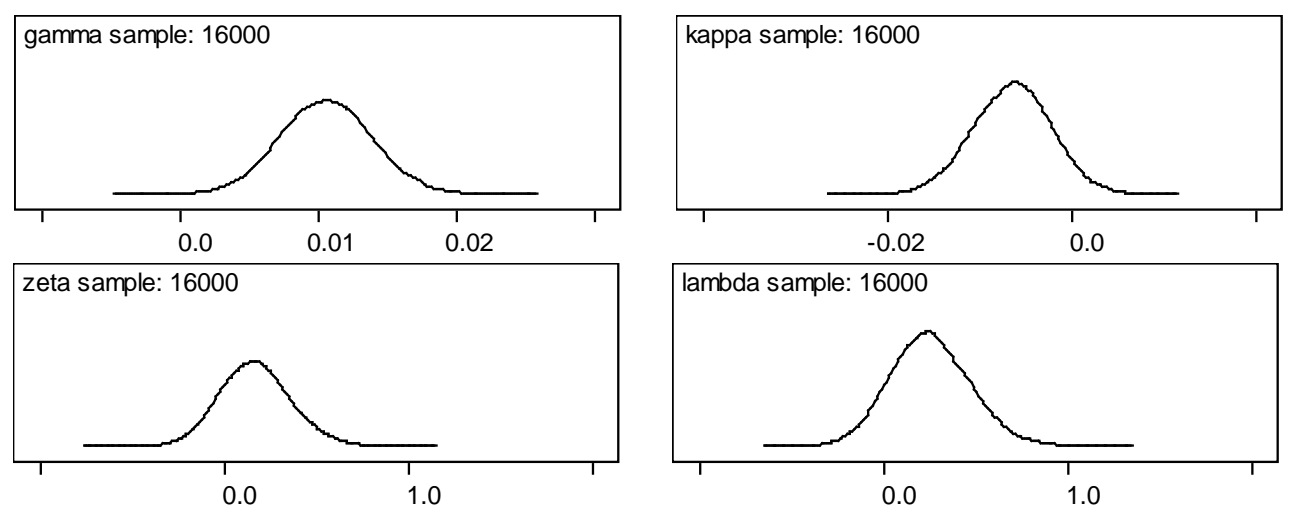

Figure 4

Figure 4 gives the sampling Distribution of Dummy Variables' Coefficients for Natural Rubber Futures. All the distributions are asymptotically symmetric.

\section{Acknowledgements}

The authors thank the referee for his careful reading of the manuscript and his helpful comments.

\section{References}

Anderson, R. W. (1984). The industrial organization of futures markets: a survey. In The Industrial Organization of Futures Markets (Edited by R. W. Anderson), 225-259. D. C. Health, Lexington, Massachusetts.

Arak, M. and Cook, R. E. (1997). Do daily price limits act as magnets? The case of treasury bond futures. Journal of Financial Services Research 12, $5-20$.

Berger, J. O. (1985). Statistical Decision Theory and Bayesian Analysis. Springer, New York.

Brennan, M. J. (1986). A theory of price limits in futures markets. Journal of Financial Economics 16, 213-233.

Chou, P. H. and Wu, S. (1998). A further investigation of daily price limits. Journal of Financial Studies 6, 19-49.

Engle, R. F. (1982). Autoregressive conditional heteroscedasticity with estimates of the variance of United Kingdom inflation. Econometrica 50, 9871007 . 
Fama, E. F. (1989). Perspectives on October 1987 or what did we learn from the crash? In Black Monday and the Future of Financial Markets (Edited by R. W. Kamphuis, Jr., R. C. Kormendi and J. W. H. Watson), 71-82. Irwin, Homewood, Illinois.

Figlewski, S. (1984). Margins and market integrity: margin setting for stock index futures and options. Journal of Futures Markets 4, 385-416.

Greenwald, B. C. and Stein, J. C. (1991). Transactional risk, market crashes, and the role of circuit breakers. Journal of Business 64, 443-462.

Hall, A. and Kofman, P. (2001). Regulatory tools and price changes in futures markets. Australian Economic Papers 40, 520-540.

Jiang, G. J., Konstantinidi, E. and Skiadopoulos, G. S. (2012). Volatility spillovers and the effect of news announcements. Journal of Banking and Finance 36, 2260-2273.

Kim, K. A. and Limpaphayom, P. (2000). Characteristics of stocks that frequently hit price limits: empirical evidence from Taiwan and Thailand. Journal of Financial Markets 3, 315-332.

Kim, K. A. and Rhee, G. S. (1997). Price limit performance: evidence from the Tokyo Stock Exchange. Journal of Finance 52, 885-901.

Lehman, B. N. (1989). Commentary: volatility, price resolution, and the effectiveness of price limits. Journal of Financial Services Research 3, 205-209.

Ma, C. K., Rao, R. P. and Sears, R. S. (1989a). Limit moves and price resolution: the case of the treasury bond futures market. Journal of Futures Markets 9, 321-335.

Ma, C. K., Rao, R. P. and Sears, R. S. (1989b). Volatility, price resolution, and the effectiveness of price limits. Journal of Financial Services Research $\mathbf{3}$, 165-199.

Mao, S. S., Wang, J. L. and Pu, X. L. (1998). Advanced Mathematical Statistics, 1st edition. Higher Education Press, Beijing.

Moser, J. T. (1990). Circuit breakers, economic perspectives. Federal Reserve Bank of Chicago 14, 2-13.

Taylor, S. J. (1986). Modeling Financial Time Series. Wiley, Chichster.

Wei, S. X. (2002). A censored GARCH model of asset returns with price limits. Journal of Empirical Finance 9, 197-223. 
Received October 20, 2012; accepted March 19, 2013.

Naisheng Wang

Financial Analyst

China Securities Index Co., Ltd

5F, Bldg B, No. 555 Ying Chun Road, Pudong, Shanghai, 200135, China

wangnaisheng@yahoo.com

Yan $\mathrm{Lu}$

Assistant Professor

Department of Mathematics and Statistics

University of New Mexico

MSC03 2150, Albuquerque, New Mexico 87131, USA

luyan@math.unm.edu 